\title{
Contributions from behavioral geography to environmental criminology
}

\begin{abstract}
Despite the great interest in the study of crime and its relation to the environment where it occurs, few works have focused on the protagonists of this phenomenon, that is, the perpetrators. The importance of the criminal behavior study at the individual level arises from the fact that crimes, even if commonly treated as event packages, are phenomena caused by individuals. In this respect, one salient contribution to the understanding of crime has risen from geography, by placing emphasis on the spatial behavior of perpetrators. The objective of this study is to discuss the main behavioral geography theories and concepts applied to the study of crime, in order to establish a dialogue with other fields of knowledge, especially the social and criminological sciences. This is an exploratory study, which brings a review of the theories and concepts that may contribute to new approaches to the study of crime, namely mental maps, awareness space, journey to crime and geographic profile.
\end{abstract}

Keywords: spatial behavior, mental maps, awareness space, crime, geographic profile
Volume 2 Issue 4 - 2018

\author{
Alexandre Magno Alves Diniz,' Antônio Hot \\ Pereira de Faria ${ }^{2}$ \\ 'Pontifical Catholic University of Minas Gerais, Geography \\ Graduate Program, Brazil \\ 2Military Police of Minas Gerais, Center for Research and \\ Graduate Studies, Brazil
}

Correspondence: Alexandre Magno Alves Diniz, Pontifical Catholic University of Minas Gerais, Geography Graduate Program, Minas Gerais, Brazil,

Email alexandremadiniz@gmail.com

Received: June 06, 2018 | Published: July 17, 2018

\section{Introduction}

Behavioral geography, as a geography subfield, began its development in the 1960s, when researchers challenged existing theories about how people made travel decisions and behaved in space. Rengert ${ }^{1}$ defines behavioral geography as the study of the spatial decision-making of individuals that precedes their behavior. Behavioral geography can be understood as a body of research interested in why and how people make spatial decisions to satisfy their needs, including shopping, entertainment, medical services and criminal activity. ${ }^{2}$

Since the beginning, behavioral geography has been applied to the research on crime decision making process, generally touching two broad areas. The first area is called behavior in space, defined by Rengert ${ }^{1}$ as a research approach which considers the geographic distribution of opportunities for crime and the social, economic, physical, and psychological constraints to criminal spatial behavior. According to this definition, the spatial structure of opportunities for crime can shape the distribution of crime. The behavior in space research is more site specific and analyzes how the combination of opportunities and constraints within an area impact crime patterns. Criminological investigations, which were heavily influenced by this area of geography, include crime pattern theory and crime opportunity frameworks. The other area of behavioral geography is called spatial behavior. This area conceptualizes individuals as active participants in crime instead of a mere passive agents responding to physical and social constraints.

The objective of this work is to discuss some of the major theories and concepts of behavioral geography applicable to the study of crime, in order to establish a dialogue with other fields of study, especially the social and criminological sciences, emphasizing the importance of space. The major motivation for this study lies in the fact that theories and concepts related to geography can contribute to foster new academic investigations, as well as present methods and techniques useful to applied science and problem solving, subsidizing public policies in security and crime prevention.

\section{Theories of behavioral geography applied to crime studies}

Among the pioneering studies involving human decisions based on representations about reality lies Wolpert' ${ }^{3}$ work on the decision to migrate. In this study, the author defines three central concepts behind migrant behavior, which serves as parameters for human locational decision-making:

1. The notion of place utility.

2. The approach of field theory to search behavior.

3. Life-cycle approach to threshold formation.

For Wolpert, ${ }^{3}$ considering human's eminently rational behavior, they will tend to locate in places whose characteristics possess or promise a relatively higher level of utility. Thus, the concept of utility of places represents can be understood as a space that offers favorable conditions to satisfy the needs of human beings. Another important concept introduced by Wolpert's ${ }^{3}$ study is the idea of action space. In the author's proposal, it refers to the immediate subjective environment, which comprises the set of utilities of place that individuals perceive, and to which they respond to. This definition of space action is similar to concept of life space, which refers to the universe of space and time where any given person can move around.

In other words, life space is a surface where the organism moves, according to its needs and perceptive apparatus.

The degree to which the individual's space of action accurately represents the physically objective world in its totality is a function that depends on the characteristics of humans and the variability of the environment. As a consequence, there is the fixation of humans with a specific place-the spatial particularism of the space of action to which they respond to. Therefore, the individual's space of action includes not only his/her current position, but a finite number of alternative places that become visible to him/her through a combination of search efforts 
and communication transmissions. The space of action refers to a set of places for which the expected utilities were defined by the individual. For the application of these ideas to the study of criminal behavior, it appears that the space of action of a given criminal will transcend its immediate district, given the likely presence of an underlying place utility that makes the criminal choose to settle. Additionally, the action space will also encompass other places where this criminal search will take place, usually during the execution of routine activities. Let us not ignore the fact that such activities are developed in order to meet the criminal's demands, which in this case may well involve the search for potential targets for crimes.

\section{Mental maps}

Mental maps, also called cognitive maps, are conceptualized by Smith $^{4}$ as "a mental description of an environment". According to Paulsen and Robinson ${ }^{2}$, a mental map can be understood as a sketch of a place or area that involves knowledge of individuals about that place or area. According to Canter \& Hodge, ${ }^{5}$ a mental map refers to inner representations of the world that people use to find their way and make decisions about what and where to do. These internal representations were explored by environmental psychologists such as Ladd ${ }^{6}$ using the device to get people to draw a sketch map of an area. Apart from many other authors, Downs \& Stea $^{7}$ showed, based on Lynch's ${ }^{8}$ seminal study, that these mental representations differ from person to person, relating closely to the actual experience of specific environments. The mental image or "map" is derived from the interaction between the active storage of information and the passive availability of environmental cues. The mental image that forms influences what the person thinks it is possible and where that possibility exists. This is a developing cyclical process. The interaction with the environments, in contrast, shapes the conceptions of the person. The place where a person performs several acts is a result of what the person knows is possible. This will be a dynamic process that will take the offender beyond his/her "routine activities" as he/she explore the possibilities of crime. It is out of these dynamic processes that the offender selects opportunities for crime. Therefore, the more one understands about environmental psychological processes, the more one can model and predict spatial criminal behavior. ${ }^{9}$

A mental map does not necessarily indicate that an individual has detailed knowledge of an entire area but suggests that a person has a mental picture of the geography of that area. Most of the time people have mental maps that are highly detailed in certain areas, holding only imprecise understandings in other areas, mostly because of the varying amount of activities they perform in space. These fragmented mental maps are the result of an individual's experience and are used to solve problems, create opinions about an area, and direct actions such as travel routes and shopping habits. ${ }^{2}$

Mental maps are formed by two sources of information: the first and most striking are the individual experiences, through knowledge about a locality as it traverses and interacts within the areas; and the second, the perception, through knowledge about an area via media and friends, seeing maps, places on TV, or reading about them.

\section{Awareness space}

Mental maps, as already discussed, contemplate areas about which people hold detailed geographic knowledge and other areas where only superficial information is available. In terms of behavioral geography, the areas in which an individual has detailed geographic knowledge are called awareness space. This is a very important concept to crime spatial analysis and journey to crime, as research shows that offenders' "search area" for criminal activity is correlated with his/her awareness space. Thus, within any given general mental map there is a more detailed area of spatial consciousness; where criminals will seek targets for committing crimes-awareness space. ${ }^{10}$
Mental maps are developed from individual experiences with their awareness space. An awareness space is defined as all places where a person has knowledge about above a certain level, even without having visited some of them. Awareness space includes activity space (the area within which the individual most often comes into contact with others and with the characteristics of the environment), an area which can expand as new locations are discovered and/or new information is collected. ${ }^{11}$

There is an important aspect about how an individual acquires their awareness space. As with mental maps, awareness space is not an inherently criminal concept. Both criminals and non-criminals gain their awareness space through the same general processes of conducting routine activities. ${ }^{12,13} \mathrm{As}$ Rossmo ${ }^{14}$ said, the area where an individual transit regularly for legitimate purposes is called the individual's activity space and it is part of individual's awareness space. Rossmo ${ }^{14}$ defines activity space as "places regularly visited by a person in whom most of the person's activities are performed." 14 This concept resembles Wolpert's ${ }^{3}$ concept of space of action, discussed previously.

An activity space contains the areas that make up the habitual geography of an individual, consisting of routinely visited places (daily or weekly) and the individual's connection ways. ${ }^{15}$ Activity space plays a central role in Brantingham and Brantingham's model of crime scene (crime pattern theory) and therefore it is an integral part of the underlying theory of geographic profiling. According to Canter and Gregory ${ }^{16}$, "where we go depends on what we know [...] what we know depends on where we go." 16

\section{Journey to crime}

Journey to Crime is an area of the criminological research interested in the distances traveled by criminals to commit crimes, specifically the distances between their homes and the places where crime is committed. ${ }^{2}$ While the idea of criminal pathways to commit crime is simple, the implications of where and why criminals travel to specific places to commit crimes impacts most criminological theories. ${ }^{17}$

According to Hodgkinsoi and Tilley ${ }^{18}$ the interest in the journey to crime began in the 1930 s, with White's ${ }^{19}$ (i.e.) study, which noted that criminals who commit crimes against property generally traveled longer distances than criminals who committed crimes against people. Turner ${ }^{20}$ analyzed delinquency behavior by a travel function (distance decay) showing that a much larger number of crime motivated travels tends to occur near the abusers' homes with the frequency falling with greater distances. Apparently, Phillips ${ }^{21}$ was the first to use the term journey to crime to describe the distances traveled by offenders to commit crimes. Harries $^{22}$ observed that the average distance traveled evolved into an analogy with the statistics of traveling to work.

These studies became more popular in the 1970s. With technological advances in the field of geography it has become much more feasible to study the spatial dynamics of crime and determine the probability of an aggressor and victim coming together in a specific space and time. Criminal standards analysis using Geographic Information Systems (GIS) with high-power computer systems, more sophisticated mapping software, and use of GPS facilitate spatial analysis.

Empirical observations on the journey to crime involved studies by Rhodes \& Conly, ${ }^{23}$ which expanded the concept of criminal commuter and showed how patterns of robbery, assault and rape in the District of Columbia followed a distance decay pattern. LeBeau ${ }^{24}$ explored travel distances of rapists in San Diego by victim-aggressor relations and by method of approach. Although situational approaches to crime prevention point to the importance of the interaction between offender, victim, and location, the searching for crime has been almost exclusively concerned with the movement of the perpetrator from his home to the crime scene. There is a substantial body of literature related to delinquent mobility patterns (largely in North America) and how these patterns may differ 
depending on the type of criminal offense committed and the specific geographic location. ${ }^{18}$

According to Rossmo, ${ }^{14}$ most criminals are limited by a buffer zone, which represents an area around the abuser's home where they commit fewer crimes. This buffering effect often occurs for two main reasons: a perception of lack of anonymity and a reduction in the number of targets. That is, while offenders often prefer to commit crimes in areas they know, they do not want to be in areas where they will be recognized. The same author ${ }^{14}$ also states that the number of potential targets increases with the distance of a fixed point, such as the residence of the aggressor For this reason, offenders cannot commit as many crimes close to home as they do within a short distance. It is important to emphasize that the buffer represents a reduced area of activity, not an area without criminal activity.

\section{Geographic profiling}

In the mid-1980s, scientists who supported police investigations ${ }^{26-28}$ realized that they could estimate where an offender would probably live based on an analysis of the geographical locations of the offender's crimes. This process of indicating the possible area where the police should look for an offender turned out to be known as geographical profiling, or North American geographic profiling. Geographic profiling is the process of determining the most likely area to find the basis of a criminal's activities through crime sites. ${ }^{14}$

According to Paulsen \& Robinson, ${ }^{2}$ although in 1986 Le Beau recognized the potential of geostatistical analysis and crime pattern research to reduce criminal investigations, it was not until 1990 that the true geographic profile was developed. The most widely recognized individual responsible for developing geographical profiles is D. Kim Rossmo, a former inspector of Vancouver's Police Department and a Doctor egress from Simon Fraser University School. Among the pioneering initiatives related to inferences about the operational base of offenders is Canter \& Gregory's ${ }^{16}$ work on serial rapists. Inferring from the geographical distribution of offenses, the authors demonstrated that the aggressor's residence tended to be the base for their activities. At that time, a great deal of publicity was being given to the contributions that some FBI agents were claiming about how they resolved crimes, resorting to a process they called the "infraction profile." When deductions about where an offender can be found were derived from the distribution of offenses on a map, it seemed appropriate to call this process geographic profiling.

Kind $^{26}$ was probably the first person to recognize the potential for investigation of geographic analysis of crime sites. In 1980 he produced a report on the location of the crimes attributed to "The Yorkshire Ripper" who had murdered 13 women during a period of five years in northern England. As a former RAF navigator, $\mathrm{Kind}^{26-30}$ assumed the task of locating the offender as a navigation challenge. Metaphorically, Kind used offending sites as fuel depots, attempting to find the ideal location for an aircraft base, by calculating the "center of gravity" of crime sites. This proved reasonably accurate in determining where criminals lived. Kind's discovery was disregarded until Canter rediscovered it five years later.

Kind showed that the average distance traveled by offenders is only one aspect of criminal spatial behavior that enables the creation of geographic profiles. He presented the second important aspect of spatial criminal behavior, that is, the possibility that many offenders have a base within the area circumscribed by their crimes. This proved to be a rather distinct finding indicating the short average distances between home and place of crime. ${ }^{30}$ In fact, the discovery that criminals tend to operate within a certain area, having a particular "criminal outreach", helped broadening the perspective beyond the ideal that offenders travel short distances. ${ }^{16}$

The path to consider the patterns of offense in relation to the place of residency was opened, rather than simply focusing on offenders whose base is close to the places crimes are committed. These spatial patterns of offenses, notably the meaning of the home, drawing attention to the psychological and perceptual environmental processes that had to be involved in criminal spatial behavior and the characteristic range of offense, led to the recognition that, in some circumstances, the basis of the criminal could be inferred with a useful degree of accuracy from relatively simple geometric calculations. This encouraged the development of software systems that allowed predictions to be made and tested by applying various geometric models to crime distributions. ${ }^{9,28}$

These initial studies demonstrated that the offense location patterns were relative and needed to be adjusted according to the scale in which the offender operated. Very dissimilar patterns were found among offenders who traveled great distances and those who traveled small distances. ${ }^{31}$ This meant that geographical profiles could be much more complex than those arising from the mere analysis of offenders who commit crimes closer to their residences. Broader models of infringement could be derived, exploiting geographical patterns irrespective of the spatial extent of offender's behavior. ${ }^{9}$

The methodology of geographic profiling is based on the model that describes the criminal hunt process. Hunting behavior refers to victim search and attack processes by an offender, and the target locations are the various locations geographically connected by a series of crimes. The patterns and methods of offender hunting activity are analyzed from a geographical perspective of crime. By establishing these standards, it is possible to delineate, through analysis of crime sites, the most likely area of residence of the offender. ${ }^{14}$

The conceptual basis of this relationship is provided by Brantingham and Brantingham's crime scene selection model, which observe that individuals, including criminals, do not move randomly through their environment. In the Brantingham and Brantingham study, researchers use knowledge about the criminal's spatial activity to predict where crimes will be committed. Geographic profiling essentially takes these ideas and inverts them. ${ }^{2}$ The research led to an algorithm for predicting the location of criminals' residence based on the crime scene geography. The resulting computational system produces risk surfaces - three-dimensional probability surfaces-that indicate the most likely area of the aggressor's residence. These are displayed through the production of isoplethic maps that provide a focus for research efforts. ${ }^{14}$

It should be considered as one of the several tools available to criminal investigators, and best used in conjunction with other police methods. Geographic crime patterns are traces that can be used to point the offender's direction when properly decoded. ${ }^{14}$

\section{Final considerations}

Based on these theoretical and conceptual aspects, it becomes clear that geography as a science presents a fundamental approach to the understanding of the criminal phenomenon as a spatial activity. This review brings together several alternatives that complement the classic theories of environmental criminology and allow integrative approaches in a theoretical-methodological framework for future works. The concepts of place utility and action space are useful for discussing the choices of crime scene locations and epistemological foundations of the underlying approaches such as mental maps and spaces of consciousness. These concepts are present non-explicitly in classical theories of criminology, such as the theory of routine activities or rational choice theory and can dialogue with such concepts in theoretical or applied works.

The journey to crime analysis allows the clarification of the processes that define behavior patterns, when comprehended at the individual level, can contribute to elucidate the criminal phenomenon in general, represented by the event packages in the indicators of crime and total rates of crime. Practically, this knowledge can contribute to the operational planning of crime prevention and combat, since knowing the modus operandi of the offenders aggregates the information of area of action 
and criminal scope, allowing a greater assertiveness in the operational planning. The geographic profiling, in contrast to the notion proposed by the journey to crime, is a methodology of predictive analysis, which seeks to locate the operational base of perpetrators, based on their serial events.

Thus, the techniques used by this methodology can be the basis for several investigative strategies, including prioritization of suspects (based on the results, suspects living in the areas most likely to receive an additional investigative focus); search for addresses based on police records systems; patrol saturation (police patrols presence may be increased where the offender is more likely to reside or search for victims); neighborhood investigations (door-to-door); among others. This study is not meant to exhaust the theme, yet its objective is to serve as a reference for future research, whether in the field of geography or in criminology, in the social sciences or for the practical application of planning and employment of resources focused on combat and prevention of crime.

\section{Acknowledgments}

None.

\section{Conflict of interest}

The author declares that there is no conflict of interest.

\section{References}

1. Rengert George. Behavioural geography and criminal behaviour. The geography of crime. USA: Routledge; 1989. 161-175 p.

2. Paulse Derek J, Robinson Matthew B. Spatial aspects of crime: Theory and practice. USA: Allyn \& Bacon; 2004. 384 p.

3. Wolpert Julian. Behavioral aspects of the decision to migrate. Papers in Regional Science. 1965;15(1):159-169.

4. Smith Christopher J, Patterson Gene E. Cognitive mapping and the subjective geography of crime. Crime: A spatial perspective. UK: Routledge; 1980. 205-218 p.

5. Canter DV, Hodge S. Mental mapping. Criminal's mental maps. In: Turnbull TS, Hendrix EH, Dent BD, editors. Atlas of crime: Mapping the criminal landscape. Phoenix, Arizona: Onyx Press, 2000. 186-191 p.

6. Ladd Florence C. Black youths view their environment: Neighborhood maps. Environment and Behavior. 1970;2(1):74-99.

7. Downs Roger M, Stea David. Maps in minds: Reflections on cognitive mapping. USA: Harper Collins Publishers; 1977. 284 p.

8. Lynch Kevin. The image of the city. England: MIT press; 1960. 103 p.

9. Canter David V, Youngs Donna E. Principles of geographical offender profiling. UK: Ashgate Publishing Ltd; 2008. 274 p.

10. Brantingham P. Notes on the geometry of crime. In: Brantingham P, editor. Environmental Criminology. Prospect Heights, IL: Waveland; 1991. 28 p.

11. Clark AN. The new Penguin dictionary of geography. London: Penguin Books; 1990. 480 p.

12. Brantingham P. Nodes, paths and edges: Considerations on the complexity of crime and the physical environment. Journal of Environmental Psychology.1993;13(1):3-28.
13. Lewin Kurt. Field Theory in Social Science. New York: Harper and Row; $1951.8 \mathrm{p}$.

14. Rossmo D Kim. Geographic profiling. Boca Raton, FL: CRC Press; 1999 $378 \mathrm{p}$.

15. Jakle John A, Brunn Stanley D, Roseman Curtis C. Human spatial behavior: a social geography. North Scituate, Mass: Duxbury Press; 1976. $315 \mathrm{p}$.

16. Canter David V, Gregory Adam. Identifying the residential location of rapists. Journal of the Forensic Science Society. 1994;34(3):169-175.

17. Rengert George F, Piquero Alex R, Jones Peter R. Distance Decay Reexamined. Criminology. 1999;37(2):427-446.

18. Hodgkinsoi Sarah, Tilley Nick. Travel-To-Crime: Homing In On The Victim. International Review Of Victimology. 2007;14(3):281-298.

19. White R Clyde. The Relation of Felonies to Environmental Factors In Indianapolis. Social Forces. 1932;10(4):498-509.

20. Turner Stanley. Delinquency and Distance. Delinquency: Selected Studies. USA: John Wiley and Sons; 1969. 11-26 p.

21. Phillips Phillip D. Characteristics and Typology of The Journey To Crime. Crime: A Spatial Perspective. USA: Columbia University Press; 1980. 167-180 p.

22. Harries Keith D. Crime And The Environment. Springfield, Il: Thomas; 1980. 163 p.

23. Rhodes William M, Conly Catherine. Crime and Mobility: An Empirical Study. USA: Environmental Criminology; 1981. 167-188 p.

24. Lebeau James L. The Journey to Rape: Geographic Distance and the Rapist's Method of Approaching The Victim. Journal of Police Science \& Administration.1987;15(2):129-136.

25. Paynich Rebecca, Hill Bryan. Fundamentals of Crime Mapping. Jones \& Bartlett Publishers; 2009. 620 p.

26. Kind Stuart S. The Sceptical Witness: Concerning the Scientific Investigation of Crime against a Human Background. USA: Routledge; 1999. $266 \mathrm{p}$.

27. Canter David. Offender Profiling and Investigative Psychology. Journal of Investigative Psychology and Offender Profiling. 2004;1(1):125-231.

28. Rossmo D Kim. Place, Space, and Police Investigations: Hunting Serial Violent Criminals. In: Wisburd D, Eck JE, editors. Crime and Place; 1995. $19 \mathrm{p}$.

29. Kind, Stuart S. Navigational Ideas and the Yorkshire Ripper Investigation The Journal of Navigation. 1987;40(3):385-393.

30. Canter David, et al. Predicting Serial Killers' Home Base Using A Decision Support System. Journal of Quantitative Criminology. 2000;16(4):457478.

31. Canter David. Offender Profiling and Investigative Psychology. Journal of Investigative Psychology and Offender Profiling. 2004;1(1):1-15. 